\title{
Mudanças de curto prazo no balanço sedimentar da Praia do Icaraí (Caucaia, Ceará) durante uma ressaca do mar
}

\author{
Short-term change in the sedimentary balance of Icaraí Beach (Caucaia, Ceará) during storm \\ surge
}

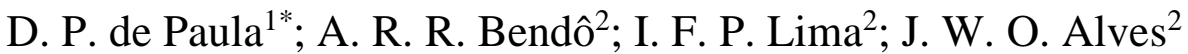 \\ ${ }^{I}$ Departamento de Engenharia Civil/Doutor em Ciências do Mar, da Terra e do Ambiente/ Laboratório de Engenharia \\ Ambiental e Geotecnologias, Universidade Estadual Vale do Acaraú, 62.040-370, Sobral-Ceará, Brasil
}

${ }^{2}$ Departamento de Engenharia Civil/Laboratório de Engenharia Ambiental e Geotecnologias, Universidade Estadual Vale do Acaraú, 62.040-370, Sobral-Ceará, Brasil

*davispp@yahoo.com.br

(Recebido em 19 de janeiro de 2016; aceito em 21 de março de 2016)

\begin{abstract}
Este artigo apresenta resultados de um experimento de campo realizado para avaliar a resposta morfológica de uma praia arenosa durante um evento de ressaca do mar. O estudo foi realizado na Praia do Icaraí, localizada no litoral da Região Metropolitana de Fortaleza, estado do Ceará. O experimento de campo foi baseado no acompanhamento contínuo de cinco seções de controle a partir de informações topográficas e oceanográficas. Foram realizadas 7 campanhas de campo (28/01/14 a 09/02/14). As respostas morfológicas dos trechos observados foram diferentes em termos de erosão e deposição. A seção limitada por dunas antropizadas (S1) apresentou erosão da berma e da praia submersa. Os trechos costeiros limitados por uma estrutura de proteção costeira (S2 a S4) apresentaram recuo da parte superior do perfil. No trecho de dunas frontais (S5), houve uma erosão generalizada da duna e da berma. De forma geral, a Praia do Icaraí é vulnerável a eventos de ressaca do mar.

Palavras-Chave: Ressacas do Mar; Erosão Costeira; Balanço Sedimentar.
\end{abstract}

This paper presents results of a field experiment conduced to evaluate the morphological answer to a sandy beach for a storm surge event. The study was realized in Icaraí Beach (Caucaia-CE) located on the coast of the Metropolitan Region of Fortaleza, Ceará state. The field experiment was based on continuous monitoring of five control sessions from topographic and oceanographic information. Was done 7 field campaigns between 01/28/2014 and 09/02/2014. The morphological response of observed excerpts was noticed were different in terms of erosion and deposition. The limited section by anthropic dunes (S1) presented berm and submerged beach erosion. Coastal stretches limited by shell-work of a coastal protection (S2 to S4) presented a decrease of the upper part of the beach profile. On the front stretch of the dune (S5) there was a general erosion of the dune and berm. The results showed this beach is quite vulnerable to storm wave action.

Key Words: Storm surge; Coastal Erosion; Sediment Balance

\section{INTRODUÇÃO}

A zona costeira é uma região governada basicamente pela interação dos agentes hidrodinâmicos (ondas, correntes e marés) e das rugosidades urbanas impostas pela ação do homem. A associação desses dois fatores pode ser observada através das variações volumétricas do nível de sedimento das praias. Essas variações podem ser de curto, médio e longo período, e qualquer tentativa de reconhecimento de seus subambientes devem levar em conta seus agentes modificadores [1].

A dinâmica costeira é a principal responsável pela formação das praias arenosas e pelos processos de erosão/deposição, que as mantêm em constantes alterações. As forçantes naturais são responsáveis pelo transporte de sedimentos e pelo modelamento do litoral, produzindo formas e feições erosivas e deposicionais bastante variáveis [2,3,4].

A ressaca do mar é um fenômeno natural que pode ser induzido por uma ação individual ou associação de forçantes naturais (e.g. onda, maré e vento). Paula et al. (2014) [5] destacam que o evento de ressaca ocorre quando há o empilhamento da massa de água junto à costa. $\mathrm{O}$ máximo nível de água alcançado (espraio máximo da onda e a sobreelevação momentânea do nível da água 
do mar) induz ao máximo alcance do espraio das ondas sobre a superfície da praia, contribuindo para rápidas mudanças no perfil praial.

$\mathrm{O}$ aumento na amplitude das ondas, na maioria das vezes, ocorre devido à atuação de sistemas meteorológicos de baixa pressão (ciclones extratropicais), os quais muitas vezes se formam em regiões afastadas da costa, e mesmo assim favorecem a agitação marítima e a propagação de ondas que atingem a região costeira, onde são modificadas ao ingressarem em águas mais rasas [6].

Segundo Vellinga (1982) [7], Ferreira (2005) [8], Silva et al. (2007) [9] e Almeida et al. (2010) [10], as mudanças mais aceleradas e bruscas no cenário costeiro (natural e/ou antropizado) ocorrem durante os eventos de alta energia, como as ressacas do mar. Para Faraco (2003) [11] e Montefalcone et al. (2010) [12], as constantes intervenções do homem na zona costeira têm alterado o balanço sedimentar ao longo das costas, gerando diminuição do suprimento de sedimentos e submetendo as praias a um permanente estado de erosão (caso observado no litoral de Caucaia). Assim, para proteger o patrimônio público e privado, e evitar que as atividades de lazer fiquem prejudicadas com a diminuição da faixa de areia das praias, diferentes métodos de proteção vêm sendo utilizados ao longo do tempo. Na maioria das vezes, esses métodos baseiam-se na colocação de estruturas rígidas sobre o litoral, na tentativa de minimizar o impacto produzido pelas ondas.

Diversos autores como Floor (2014) [13], Pye et al. (2007) [14] e Toldo Jr et al. (2013) [15], destacaram que o frágil equilíbrio das praias depende do seu balanço sedimentar, que, por sua vez, dependerá do movimento de sedimentos entre o sistema terra/mar. O modelo disponibilizado na Figura 1 é utilizado largamente para descrever o balanço sedimentar das praias a partir do transporte sedimentar. Nele, é perceptível que os sedimentos são transportados, principalmente, pelos rios em direção ao mar, de onde são carreados longitudinalmente pela deriva litorânea. Logo, o material sedimentar será direcionado às praias pela ação das ondas. Também vale destacar que na porção submersa da praia é possível a formação de bancos de areia, que serão retrabalhados por ondas mais energéticas (swell). Nesse caso, os sedimentos serão transportados em direção às praias, especialmente para a zona intertidal, onde parte delas será levada pelo vento em direção ao continente, configurando uma perda para o perfil praial, mas um ganho geral para o sistema de abastecimento sedimentar da zona costeira, se as mesmas chegarem até os rios ou estuários. Por outro lado, a maior perda de sedimentos ocorre através da ação das ondas mais energéticas sobre as praias, remobilizando grandes volumes de areias para fora da zona de sua influência, contribuindo para um balanço sedimentar negativo da praia (situação de erosão).

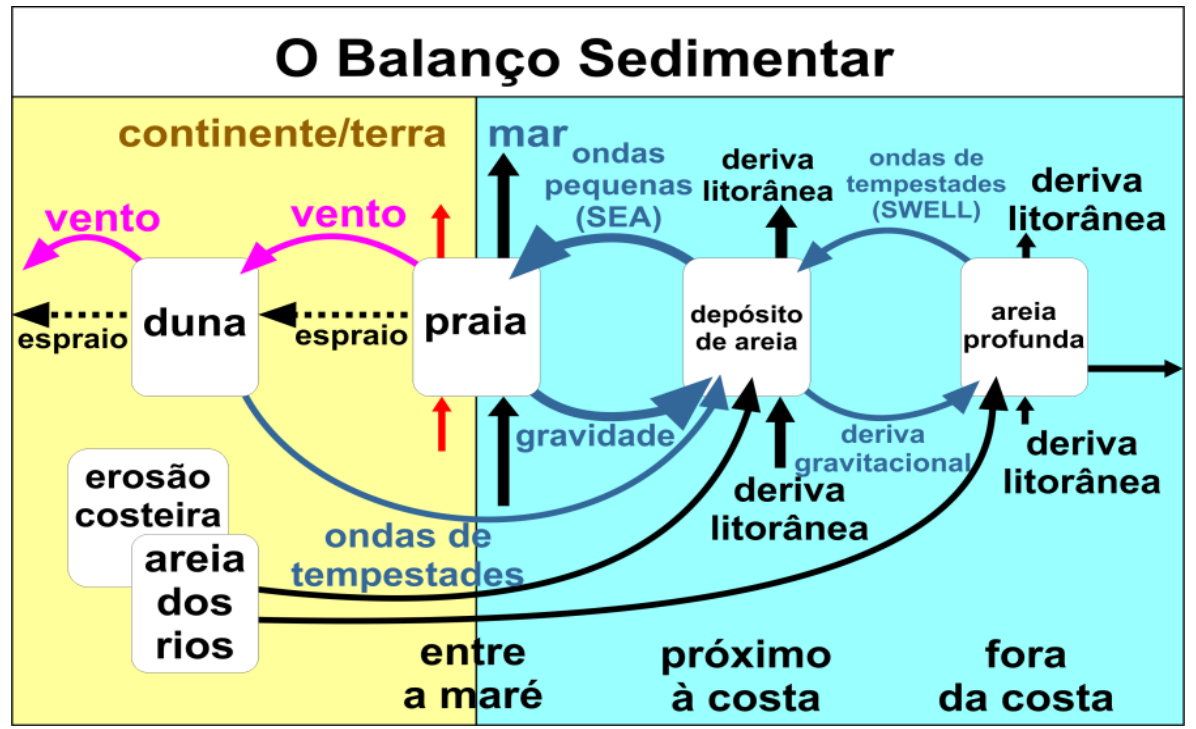

Figura 1. Modelo do balanço sedimentar em ambientes praiais. Adaptado de Floor (2014) [13]

A situação aludida anteriormente por Faraco (2003) [11] pode ser observada no litoral de Caucaia, especialmente na Praia do Icaraí (objeto de estudo desta pesquisa). Durante os últimos vinte anos, diversas obras rígidas foram construídas nessa praia com objetivo de controlar o processo de erosão costeira. Por último, em 2011, foi construída, ao longo de 1,5 km, uma estrutura rígida do tipo Bagwall para conter o avanço do mar na região. 
Como destacado por Komar e Mcdougal (1988) [16], Dias (1993) [17], Zyserman et al. (2005) [18] e Zasso et al. (2013) [19], a construção de estruturas rígidas no litoral afeta diretamente o transporte sedimentar para as praias adjacentes, e por vezes, também debilitam a deriva litorânea local. Os litorais com baixo transporte sedimentar por deriva litorânea são caracterizados por possuir sua linha de costa totalmente artificializada por obras de proteção costeira (caso observado na Praia do Icaraí), além de um forte processo de erosão das dunas frontais [17]. Nesse caso, o presente estudo avaliou as alterações morfológicas por meio do balanço sedimentar, induzidas durante um evento de ressaca do mar que ocorreu no litoral de Caucaia (Região Metropolitana de Fortaleza-CE) entre os dias 28/01/14 e 09/02/2014. O litoral de Caucaia foi escolhido como área de estudo por já ter sido uma das áreas balneares mais importantes do litoral do Ceará.

\section{2. ÁREA DE ESTUDO}

O litoral de Caucaia está localizado a menos de $20 \mathrm{~km}$ da cidade de Fortaleza, capital do estado do Ceará, integrando a Região Metropolitana de Fortaleza - RMF. Nesse trecho costeiro, estão localizadas algumas das principais praias do Ceará, a saber: Icaraí, Tabuba e Cumbuco. A Praia do Icaraí, objeto de estudo desta pesquisa, localiza-se no domínio leste do litoral de Caucaia. É um trecho costeiro de pouco mais de $3,5 \mathrm{~km}$, caracterizado por uma linha de costa fortemente antropizada e com problemas de erosão costeira que já resultaram em perda de faixa útil de praia bem como danos ao patrimônio edificado (Figura 2).

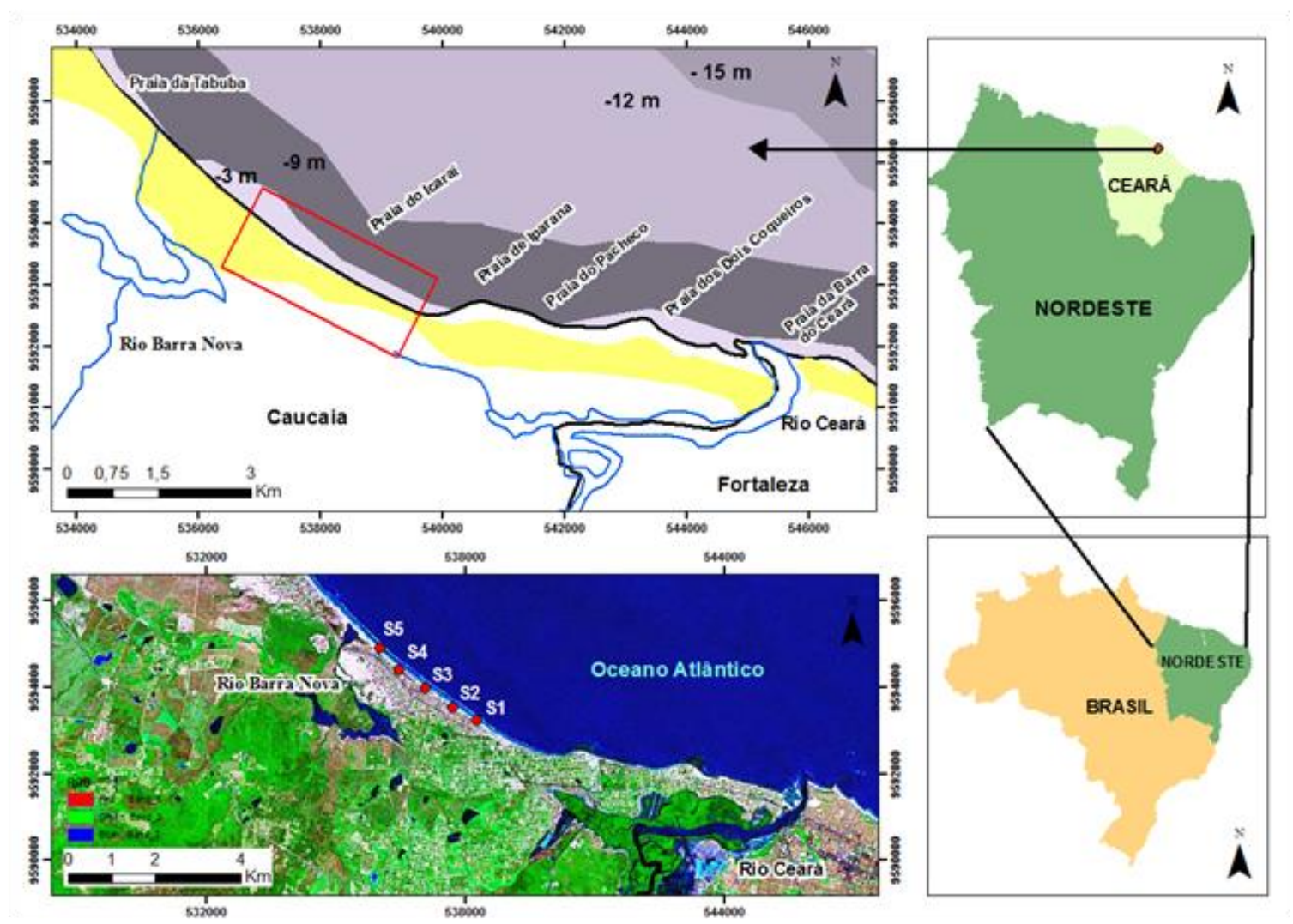

Figura 2. Área de estudo no litoral de Caucaia (Ceará, Brasil), destacando a Praia do Icaraí (delimitada em vermelho).

Desde meados do século XX, o litoral do município foi procurado com finalidades balneares, tendo-se erguido, junto à costa, diversos condomínios, casas de veraneio, barracas de praia e demais infraestruturas turísticas. O trecho costeiro do Icaraí tem sofrido uma evolução acentuada ao longo das últimas quatro décadas, como resultado não só da vilegiatura que se desenvolveu entre as décadas de 1970 e 1980, mas também da erosão costeira que destruiu parte do patrimônio edificado entre as décadas de 1990 e 2000. Essa situação levou à artificialização do litoral por obras rígidas 
de proteção costeira entre os anos de 2000 e 2010, nomeadamente enrocamentos, muros de alvenaria e estruturas de concreto. Para Paula et al. (2013) [20], em sua plenitude, a Praia do Icaraí foi afetada pela erosão costeira, onde a artificialização por estruturas urbanas foi superior a $60 \%$.

Entre 2010 e 2013, o que se observou foi o declínio das atividades socioeconômicas que se desenvolviam a beira-mar, mesmo após a instalação de uma estrutura de contenção de blocos de concreto denominada de Bagwall [20]. A estrutura de proteção não teve o êxito esperado (colapsou mais de três vezes) e a erosão costeira foi agravada ainda mais pela situação climática da região (há mais de três anos com chuvas abaixo da média histórica). Majoritariamente, os sedimentos que chegam até as praias possuem origem continental, ou seja, derivam das descargas sólidas fluviais. No momento em que há diminuição nos valores de precipitação, também há diminuição do abastecimento sedimentar fluvial em direção à zona costeira, por consequência, a erosão costeira é agravada por falta de sedimentos. Atualmente, a Praia do Icaraí é uma área de risco costeira onde os valores ambientais, paisagísticos e sociais foram perdidos (Figura 3).

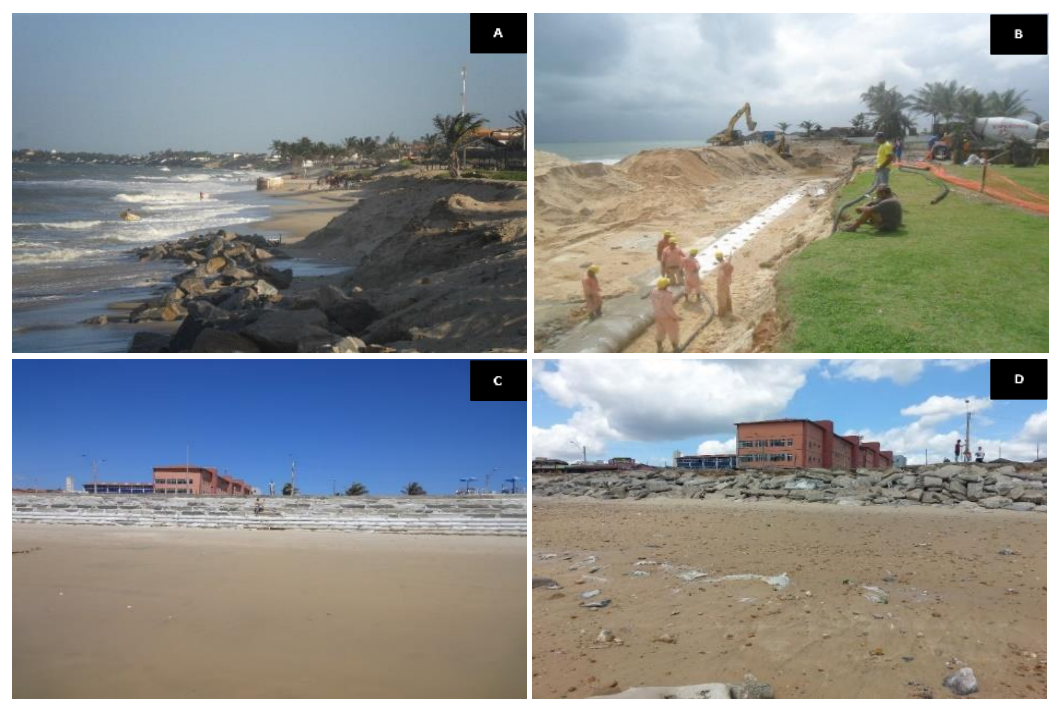

Figura 3. Evolução de trechos da Praia do Icaraí. As fotos evidenciam um ciclo erosivo - erosão (A / 2010), adaptação e proteção (B, C / 2010 e 2011) e novamente erosão (D / 2014).

Esse trecho costeiro também é caracterizado pela presença de dunas frontais no extremo oeste e falésias no extremo leste. Frequentemente existem, paralelamente à linha de costa, afloramentos de rochas de praia. Percorrendo o litoral, é possível observar os sedimentos dos Tabuleiros PréLitorâneos pertencentes à Formação Barreiras que, em alguns trechos, são recobertos por vastos campos de dunas. Trata-se de uma costa aberta com zona de surfe, variando entre $50 \mathrm{~m}$ e $80 \mathrm{~m}$, contendo de 3 a 4 linhas de arrebentação bem definidas. A maior zona de surfe se concentra na área central dessa praia, diminuindo a largura em direção às extremidades. Moura et al. (2012) [21], baseado em imagens de satélite, determinaram taxas de recuo da linha de costa da ordem de 7,6 m (próximo de $1 \mathrm{~m} / \mathrm{ano}$ ) entre 2004 e 2011.

O clima com influência semiárida apresenta baixa amplitude térmica anual (valor médio da máxima é $30^{\circ} \mathrm{C}$ e mínima de $24^{\circ} \mathrm{C}$ ). As condicionantes climáticas são influenciadas pela ação da Zona de Convergência Intertropical - ZCIT e pelas variações sazonais de fenômenos como El Niño (períodos prolongados de estiagem) e La Niña (marca o período com precipitações acima da média da região).

De acordo com dados da tábua de maré da Diretoria de Hidrografia e Navegação - DHN, as marés da região são do tipo semidiurnas com regime de mesomarés, apresentando valores mínimos de até -0,2 m e máximos de 3,2 $\mathrm{m}$. Segundo Silva et al. (2011) [22], as ondas predominantes na região são do tipo sea, com Hs médio de $1,35 \mathrm{~m}$ e picos de até $2,61 \mathrm{~m}$. O período médio é de $6,8 \mathrm{~s}$ e direção preferencial no quadrante de $40-60^{\circ}$. O mesmo autor também indica a presença, em menor escala, de ondas do tipo swell com período de pico acima de $10 \mathrm{~s}$, altura que pode ultrapassar 2,5 m e direção predominantemente de N/NE. 


\section{MATERIAL E MÉTODOS}

Para determinar o balanço sedimentar na Praia do Icaraí foram estabelecidas 5 seções de controle (nomeadamente S1, S2, S3, S4 e S5) (Figura 2). O principal critério utilizado para definição das seções foi o tipo de ocupação da costa - dunas antropizadas (S1), áreas estabilizadas por obras de proteção costeira (S2 a S4) e dunas naturais (S5). As seções 1 (leste) e 5 (oeste) estão localizadas nos extremos da praia, enquanto que as seções de 2 a 4 estão na área central da praia.

No experimento de campo, foram efetuadas 7 campanhas consecutivas de topografia praial, entre os dias 28/01/14 e 09/02/14. O primeiro levantamento ocorreu um dia antes do início do evento de ressaca do mar, enquanto que o último ocorreu sete dias após o término do evento, permitindo avaliar as alterações volumétricas da praia subordinada ou não a um regime de alta energia.

A topografia da praia obedeceu ao método da Estadia [23]. Em cada campanha, foi realizado um levantamento detalhado das cotas topográficas do trecho da praia emersa e submersa, permitindo, assim, avaliar o transporte de areias e as variações volumétricas. Os perfis foram georreferenciados e levantados com auxílio de um DGPS (Differential Global Positioning System) com precisão de $\pm 5 \mathrm{~mm}$. Todos os perfis praiais foram referenciados ao zero hidrográfico $(\mathrm{ZH})$ da Diretoria de Hidrografia e Navegação da Marinha - DHN.

As diferenças altimétricas observadas dia após dia permitem calcular a entrada e a saída de sedimentos do sistema, ou seja, o balanço sedimentar da praia. As informações altimétricas dos perfis de praia foram convertidas em geodados do tipo Grid e incorporadas em rotinas de programação estabelecidas para o cálculo do volume. O balaço sedimentar da praia foi executado segundo o método empregado por Souza (2012) [24], que avalia a relação entre as perdas/saídas e os ganhos/entradas de sedimentos na praia. Logo, não é calculado o balanço do primeiro dia de análise (28/01/2014), pois não há dados de seu dia anterior. Na confecção das rotinas de variação volumétrica, foi utilizado o software Scilab 5.5.1, desenvolvido para cálculo numérico. O programa aceita interações gráficas $2 \mathrm{D}$ e 3D, além de permitir modelagem de sistemas dinâmicos, como é o caso das praias.

Os dados referentes ao clima de onda e a variação maré foram cedidos pela Companhia de Integração Portuária do Ceará (CEARAPORTOS) [25]. Os parâmetros de ondas e marés foram registrados através de sensor acústico do tipo AWAC (frequência de $600 \mathrm{kHz}$ ). Os dados de vento foram coletados em cada seção de monitoramento com auxílio de um anemômetro digital portátil. As medições foram realizadas a uma altura de $5 \mathrm{~m}$, durante o intervalo de 5 minutos. A direção foi aferida com uma bússola tradicional analógica.

\section{RESULTADOS E DISCUSSÃO}

\section{Condições oceanográficas que impulsionaram o evento de ressaca do mar}

A ressaca do mar observada nesse estudo teve como principal agente forçador a onda. Nesse caso, a coincidência com uma maré de sizígia potencializou o evento, pois o nível de água a ser deslocado verticalmente foi maior, atingindo cotas topográficas continentais que não são atingidas normalmente pelo alcance máximo do espraio da onda. Esse é um dos sistemas que podem levar à ocorrência de uma ressaca do mar no litoral do estado do Ceará. Os demais sistemas naturais que podem induzir sobrelevação do nível do mar estão ligados a outras forçantes: o vento (mais atuante no segundo semestre do ano) e as marés equinociais.

No controle das condições oceanográficas (ondas, ventos e marés), foi possível perceber a influência da agitação marítima nas modificações morfológicas dos perfis praiais. A altura significativa de onda (Hs) variou de $0,8 \mathrm{~m}$ a $1,5 \mathrm{~m}$, com direção predominante de N/NE e período médio de onda de $8,2 \mathrm{~s}$. Os ventos predominantes tinham direção $\mathrm{E} / \mathrm{NE}$, assumindo valores máximos de $9,0 \mathrm{~m} / \mathrm{s}$ e mínimos de $4,5 \mathrm{~m} / \mathrm{s}$. A velocidade do vento foi decaindo do primeiro dia do experimento até o último dia. Durante o pico de ressaca do mar, a velocidade média foi de $5,5 \mathrm{~m} / \mathrm{s}$. A amplitude média de maré variou de 2,0 m (28/01/14) a 3,1 m (02/02/14). Durante o máximo Hs das ondas de ressaca do mar, a amplitude média das marés ultrapassou os $3,0 \mathrm{~m}$. 


\section{Variação morfológica do perfil praial}

A variação volumétrica do perfil indica que, no primeiro dia efetivo de ressaca do mar (29/01/14), houve um aumento generalizado das cotas topográficas. Tomando por exemplo a seção 5 (área de dunas não antropizadas), houve um ganho de $446 \mathrm{~m}^{3}$ de areia, isso em comparação com o dia anterior (28/01/14), em que não havia iniciado o evento de ressaca do mar. Na seção 1 (área de dunas antropizadas), o ganho sedimentar foi de $16 \mathrm{~m}^{3}$ de areia, enquanto no trecho compreendido entre o S2 e o S4 (área intervencionada por uma obra rígida), o ganho sedimentar médio foi de 101 $\mathrm{m}^{3}$ de areia.

\section{Seção 1}

Individualizando a análise das variações volumétricas, foi possível perceber que, após o primeiro dia do evento, a seção 1 entrou em erosão contínua, tendência que se manteve até sete dias após o término do evento. No perfil de praia (Figura 4), é possível observar dois trechos distintos de erosão - o primeiro na praia emersa, onde as perdas volumétricas se concentram na parte alta da praia (entre as distâncias de $15 \mathrm{~m}$ e $30 \mathrm{~m}$ ), atingindo a base da escadaria de acesso à praia; o segundo na praia submersa (entre as distâncias de $70 \mathrm{~m}$ e $215 \mathrm{~m}$ ), resultando numa variação vertical de 80 $\mathrm{cm}$.

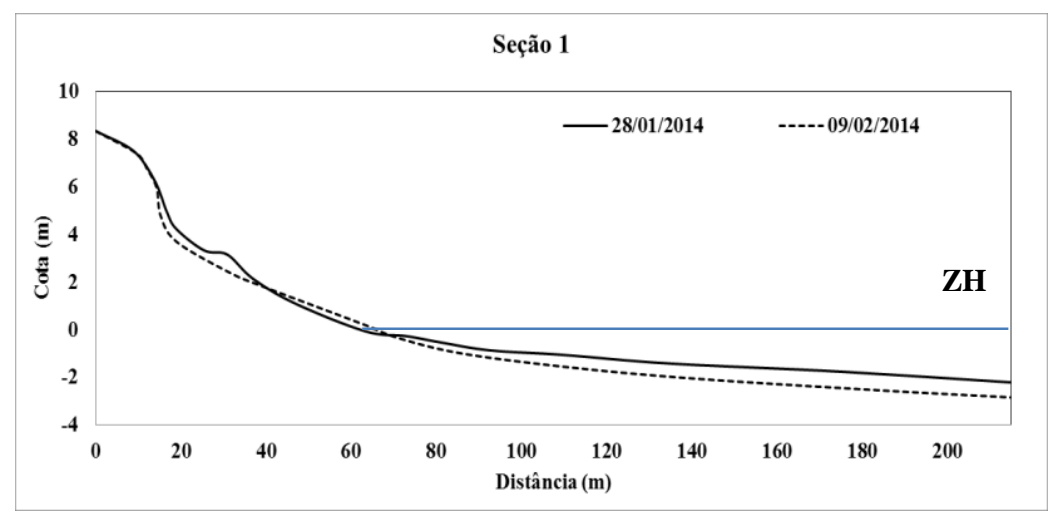

Figura 4. Máxima variação vertical dos perfis de praia da seção 1 realizados entre os dias 28/01/14 e 09/02/2014. Perfis referenciados ao Zero Hidrográfico (ZH).

De forma geral, esse trecho costeiro é bastante vulnerável à ação das ondas de ressaca do mar. Durante o evento observado, o espraio máximo da onda atingiu a cota de 5,8 m. Passados sete dias do evento, a praia não apresentou recuperação do volume inicial de areia, o que pode ser decorrente da ocupação das dunas, debilitando o transporte sedimentar entre o sistema praia-duna, designadamente diminuído o poder de resiliência ambiental. $\mathrm{O}$ ZH foi deslocado em direção à base da infraestrutura urbana. Nesse caso, o espraio máximo da onda consegue atingi-la, causando danos ao patrimônio edificado.

\section{Seção 2}

Nesta seção, a praia é limitada por uma estrutura rígida de concreto em forma de escadaria. $\mathrm{O}$ seu formato foi projetado para dissipar a energia das ondas e aprisionar sedimentos. Durante o evento de ressaca do mar foi observada uma erosão congênita da base da obra e transporte de areia para a parte inferior do perfil, onde as areias se acumularam na retaguarda da bancada de rochas de praia dispostas paralelamente à linha de costa. Posteriormente, as areias retidas foram transportadas em direção à praia submersa, quando da diminuição da energia da agitação marítima. Houve um aumento no volume de areia durante os dias mais energéticos do evento, enquanto nos dias em que o evento perdeu energia houve diminuição do volume de areia. Aparentemente, esse trecho costeiro 
foi beneficiado com a erosão da seção 1 (ao leste), havendo um componente importante de transporte lateral ou longitudinal de areias.

Após o término do evento, a praia apresentou relativa recuperação (Figura 5). O trecho à retaguarda das rochas de praia apresentou-se erosivo, em virtude do espraio máximo da onda ter diminuído o seu alcance. Logo, o trecho mais ativo do perfil se concentrou entre as distâncias de $55 \mathrm{~m}$ e $85 \mathrm{~m}$. O ZH estava na parte inferior do perfil, a $50 \mathrm{~m}$ da base da obra, mantendo uma estabilidade nesse trecho de praia emersa que se encontra sitiado continentalmente (pela obra) e maritimamente (pelas rochas de praia). De fato, a estabilidade desse setor se deu pela atuação das rochas de praias na dissipação da energia de onda, e depois, em menor grau, pela atuação da obra.

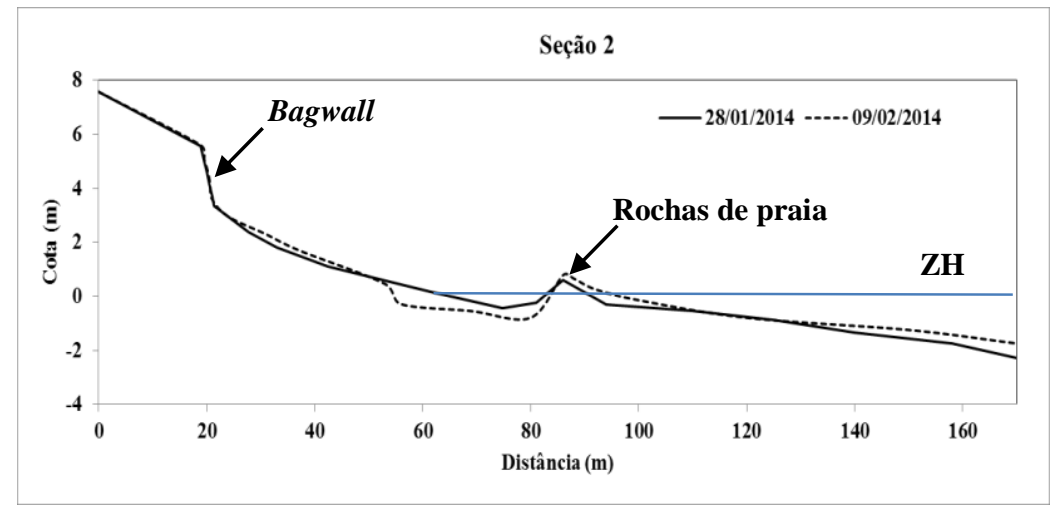

Figura 5. Máxima variação vertical dos perfis de praia da seção 2 realizados entre os dias 28/01/14 e 09/02/2014. Perfis referenciados ao Zero Hidrográfico (ZH).

\section{Seção 3}

Na seção 3 (área central da obra), não foi possível avaliar a influência da obra na variação volumétrica da praia, pois a mesma se encontra totalmente danificada. Durante o evento monitorado, o perfil respondeu de forma diferente à ação da agitação marítima. Nos dois primeiros dias da ressaca do mar (energia moderada), o perfil apresentou discreto ganho volumétrico, enquanto que, nos dois dias subsequentes (alta energia), o perfil apresentou tendência erosiva. Após o término do evento, houve recuperação parcial da faixa de praia, pois houve erosão acentuada da alta praia (que deveria ter sido protegida pela obra danificada), resultando em recuo de $5 \mathrm{~m}$ da linha de costa em poucos dias (Figura 6). A praia submersa também sofreu erosão, apresentando variação vertical de 1,2 m. Nesta seção, o ZH estava a menos de $25 \mathrm{~m}$ da linha urbana (antiga obra) e o espraio máximo das ondas chegou a ultrapassar a cota limítrofe desse trecho costeiro urbano de 5 metros, ocasionando danos físicos.

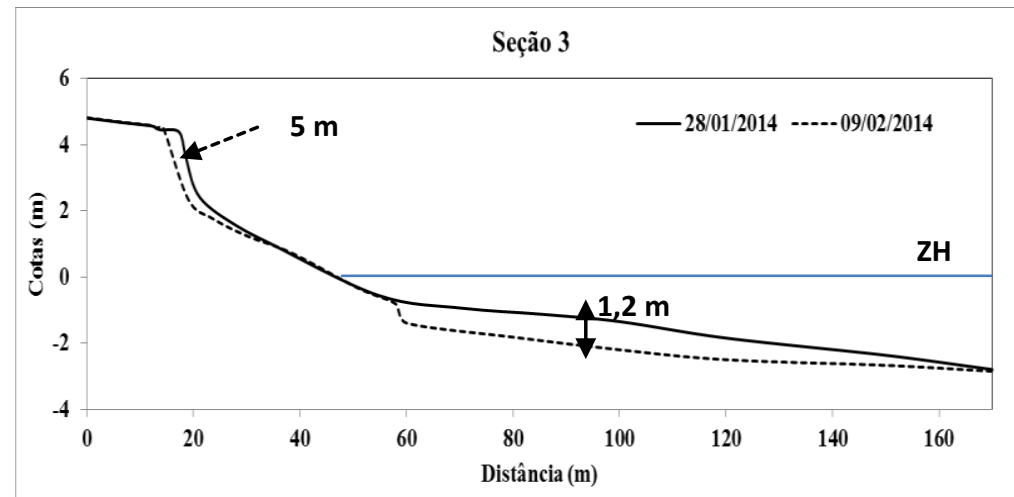

Figura 6. Máxima variação vertical dos perfis de praia da seção 3 realizados entre os dias 28/01/14 e 09/02/2014. Perfis referenciados ao Zero Hidrográfico (ZH).

\section{Seção 4}

A seção 4 representa o extremo oeste da obra, caracterizada por uma robusta alta praia em seu volume sedimentar, que só foi atingida pelo espraio máximo das ondas quando da ocorrência do 
pico do evento. Outra característica dominante desta seção foi o ganho de sedimentos quando houve erosão da seção 3 (localizada ao leste). De forma geral, a seção 4 teve comportamento estável durante todo o evento, exceto no último dia da ressaca do mar, quando houve o ganho de mais de $300 \mathrm{~m}^{3}$ de areia, contrastando com a perda de mais de $270 \mathrm{~m}^{3}$ de areia da seção 3 . Este perfil foi caracterizado por intensa mobilidade sedimentar entre as praias emersa (a partir da distância de 40 m) e submersa (até à distância de $180 \mathrm{~m}$ ). Isso ocorre devido à robustez da alta praia, que restringe a zona de espraio à parte inferior do perfil da praia. Após a passagem do evento, houve relativa recuperação da praia em relação ao primeiro dia de experimento (Figura 7). O ZH estava a mais de $60 \mathrm{~m}$ da base da obra e a zona de espraio estava concentrada no trecho entre $40 \mathrm{~m}$ e $80 \mathrm{~m}$, o que, de certa forma, contribuiu para a estabilidade da alta praia.

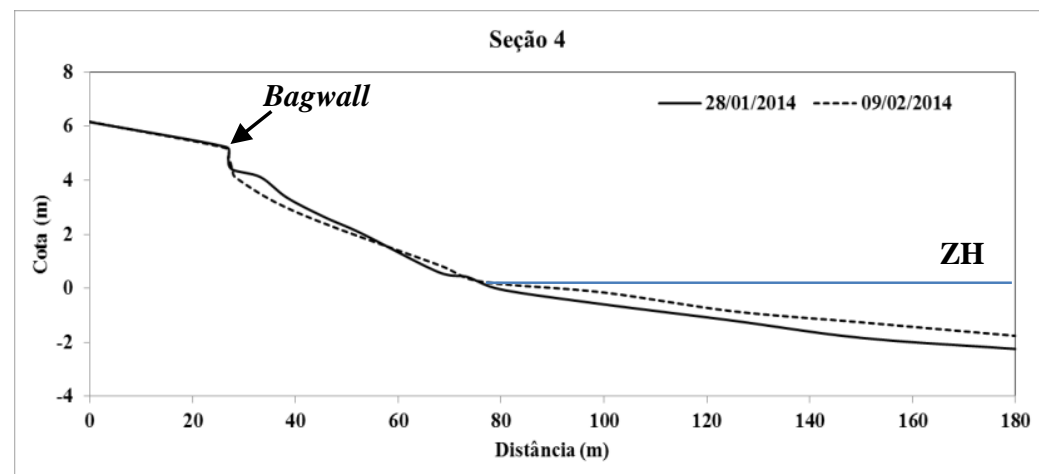

Figura 7. Máxima variação vertical dos perfis de praia da seção 4 realizados entre os dias 28/01/14 e 09/02/2014. Perfis referenciados ao Zero Hidrográfico $(\mathrm{ZH})$.

\section{Seção 5}

A seção 5 (extremo oeste da área de estudo), localizada na região de dunas não antropizadas, apresentou erosão a partir do segundo dia da ressaca do mar. Entre o primeiro dia e o segundo dia, houve perda volumétrica de $600 \mathrm{~m}^{3}$ de sedimentos, rebaixando as cotas topográficas da face de praia e facilitando o solapamento da base da duna pelas ondas de ressaca. Houve recuo de $5 \mathrm{~m}$ da crista da duna entre o primeiro e o último dia do experimento (Figura 8), situação aludida não por regime de galgamento (overwash), mas sim por regime de colisão. Outra característica desse evento de ressaca foi o deslocamento da ZH em direção à alta praia. Neste setor, o ZH foi deslocado para a base da duna, o que facilitou a sua erosão.

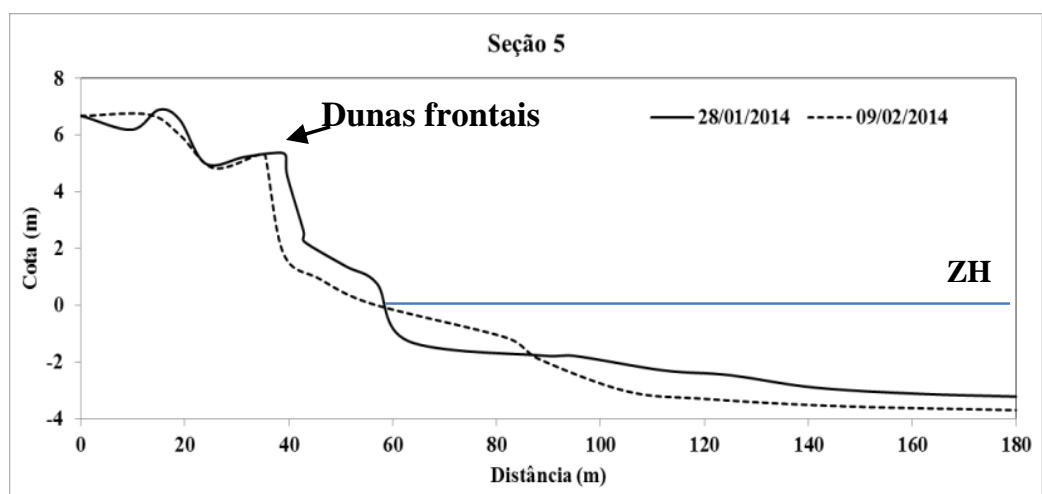

Figura 8. Máxima variação vertical dos perfis de praia da seção 4 realizados entre os dias 28/01/14 e 09/02/2014. Perfis referenciados ao Zero Hidrográfico (ZH).

O perfil de praia da seção 5 , por se tratar de um ambiente com baixa interferência antrópica e com a retaguarda limitada por dunas frontais, apresentou um processo natural de recuperação da berma após o fim do evento de ressaca do mar (Figura 9), diferentemente do ocorrido nas seções em que há uma estrutura rígida limitando a praia. 


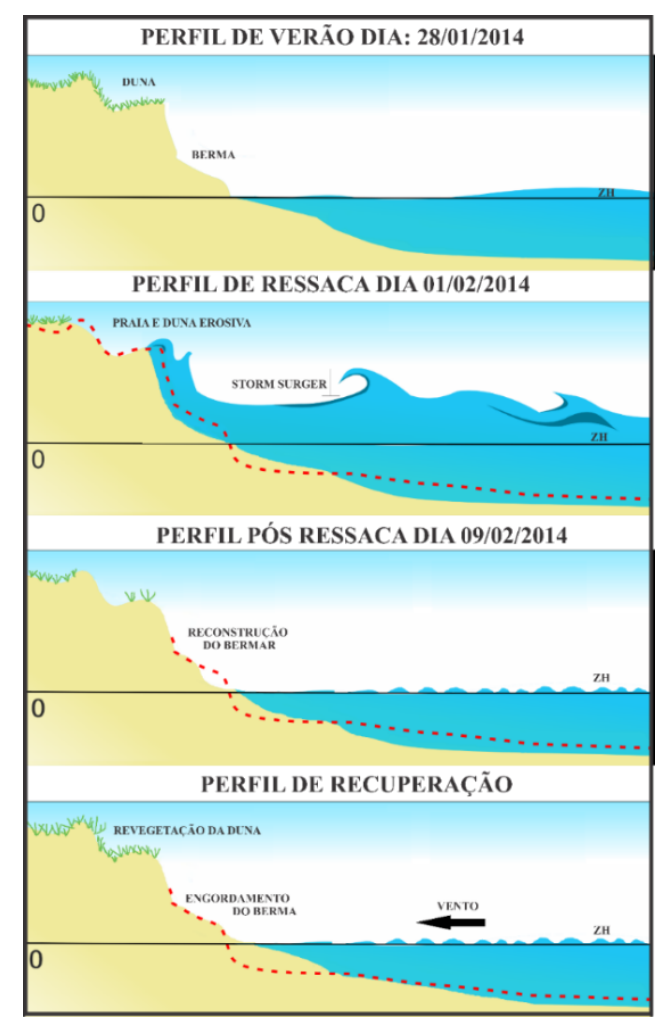

Figura 9. Estágios evolutivos do perfil de praia da seção 5. Nota: A quadra chuvosa no Ceará ocorre no verão do hemisfério sul.

\section{Balanço Sedimentar}

O balanço sedimentar mostrou ciclos de erosão e deposição durante o período monitorado, o que é normal, considerando que o experimento foi realizado durante um evento de ressaca do mar que possui variação diária de energia de onda, amplitude de maré e velocidade de vento. Ao longo de todas as seções monitoradas, foi possível observar um acréscimo no nível de areia após o primeiro dia de ressaca do mar (29/01/14), onde as maiores variações foram observadas nos perfis $\mathrm{S} 3\left(+143,2 \mathrm{~m}^{3}\right.$ de sedimentos) e S5 (+446,4 $\mathrm{m}^{3}$ de sedimentos). Nesse caso, as ondas de ressaca transportaram sedimentos da praia submersa para a praia emersa.

Avaliando o balanço sedimentar de forma pontual, podemos observar que na seção 1 (dunas antropizadas), a praia não recuperou a robustez inicial após sete dias do evento, apresentando deficit no seu balaço sedimentar final (-50 $\mathrm{m}^{3}$ de areia). Quando o balanço sedimentar é negativo, isto é, quando a saída/perda de sedimentos é maior que a entrada/ganho de sedimentos, ocorre deficit sedimentar, predominando o processo erosivo. Isso acarretou diminuição gradual da largura da praia e retração da linha de costa.

Na seção 2 foi observado que, nos três primeiros dias do evento de ressaca do mar, houve o acréscimo médio de $95 \mathrm{~m}^{3}$ de areia, seguido de dois dias de perdas consideráveis ( $367 \mathrm{~m}^{3}$ de areia). No balanço global da seção, houve discreto deficit sedimentar $\left(-16,5 \mathrm{~m}^{3}\right)$, o que não comprometeu a estabilidade do perfil de praia.

Na seção 3 foi observado que, após o primeiro dia do monitoramento, houve aumento no nível de areia de $143 \mathrm{~m}^{3}$ de areia. No segundo dia da ressaca do mar, foi registrada a estabilização no volume sedimentar do perfil, e do terceiro dia em diante, foram registradas perdas sedimentares, tal como ocorrido no S2, onde a maior delas foi no último dia do evento, tendo um valor de $-246 \mathrm{~m}^{3}$ de areia. Nesse perfil, foi observada a rápida recuperação da praia após o término do evento, gerando um superavit de areia superior a $270 \mathrm{~m}^{3}$. Porém a situação aludida foi influenciada diretamente pela ação do homem, que após a ressaca do mar, utilizou pedras e areias para proteger a alta praia, o que influenciou em um pico positivo do balanço sedimentar sete dias após o evento, descaracterizando o balanço final dessa seção. 
Na seção 4, como já destacado anteriormente, a alta praia é bastante robusta, o que impede, em situação de alta energia, a ocorrência de espraio máximo ultrapassando a crista da berma. Esse perfil apresentou comportamento estável sem grandes ganhos ou perdas sedimentares. A maior parte do acréscimo de volume foi na região submersa da praia; apresentando um balanço positivo superior a $100 \mathrm{~m}^{3}$ de sedimento.

Na seção 5, só houve balanço negativo no segundo dia do evento, em que a perda sedimentar foi de $600 \mathrm{~m}^{3}$ de sedimentos. Nos dias subsequentes e até a passagem do evento, o balanço sedimentar foi positivo. Isso só ocorreu porque houve erosão da duna frontal (com respectivo recuo) e os sedimentos foram remobilizados em direção à zona inferior do perfil, onde se depositaram. Comparando o primeiro e o último dia do experimento, observou-se que a recuperação da robustez da praia levou mais de sete dias. O balanço sedimentar integral do trecho costeiro monitorado pode ser observado na Figura 10.
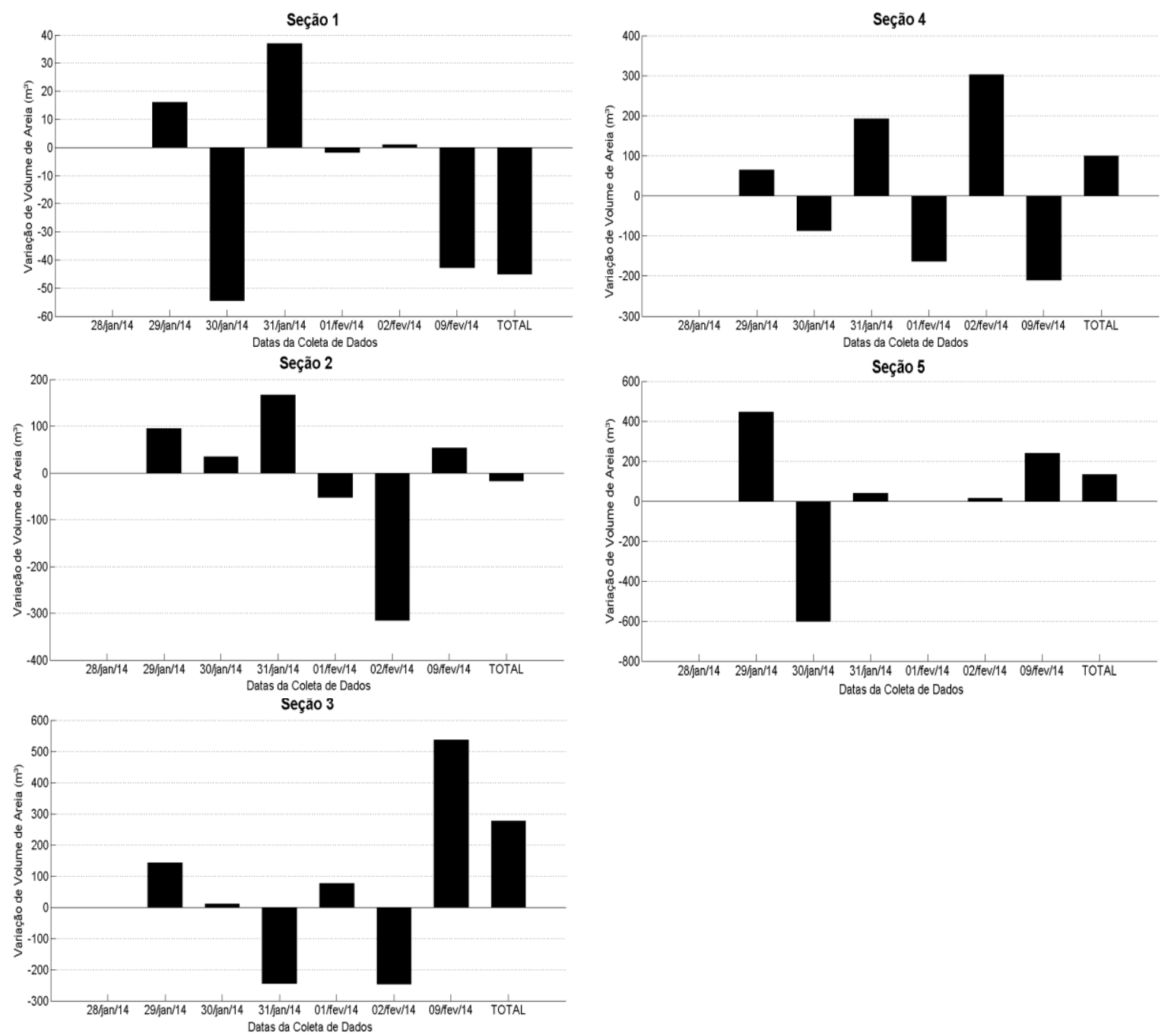

Figura 10. Balanço sedimentar dos perfis amostrados na Praia do Icaraí, entre os dias 28/01/14 e 09/02/14, durante um evento de ressaca do mar.

\section{CONCLUSÃO}

O experimento realizado se mostrou eficiente para avaliar as respostas do perfil de praia a uma forçante mais energética do que a normalmente dominante. Os danos mais severos causados ao patrimônio edificado costeiro, no Ceará, ocorrem geralmente durante a atuação de um evento de ressaca do mar, situação que já é bem conhecida. Diferentemente das alterações morfológicas 
induzidas em curta escala, essas são deficientemente conhecidas no litoral estudado. Nesse caso, uma avaliação das respostas do perfil praial através do balanço sedimentar se mostrou eficaz no entendimento do sistema como um todo - erosão e deposição.

$\mathrm{Na}$ transição do período de agitação marítima dominante para uma situação de ressaca do mar, houve um aterramento generalizado de todos os trechos monitorados, o que demonstrou a existência de depósitos de areia na praia submersa, remobilizados pela atuação das ondas de ressaca em direção ao perfil emerso da praia. Já durante o estágio inicial da ressaca do mar, a berma, em todos os setores da Praia do Icaraí, foi atingida, havendo diminuição do nível de areia nos trechos com dunas antropizadas (S1) e naturais (S5).

No pico energético do evento, o espraio máximo das ondas atingiu a linha de base das dunas e da estrutura de proteção. No primeiro caso, há uma situação diferenciada para os trechos limitados por dunas - quando antropizadas, a variação volumétrica foi extremamente negativa. Já no trecho não antropizado, houve remobilização das areias para o trecho inferior do perfil. Tratando-se do trecho com estrutura de proteção, o que se observou foi a diminuição do nível de areia da base da estrutura, expondo por vezes o número máximo de degraus (onze) que geralmente não são vistos com o clima de ondas dominante. Nesse caso, houve um deslocamento do zero hidrográfico em direção à base da obra, enquanto que, na zona de dunas naturais, o zero hidrográfico centrou-se na base da duna, o que explica as intensas e rápidas variações volumétricas do perfil.

$\mathrm{O}$ trecho do perfil S2 foi o que apresentou melhor estabilidade durante o evento. Isso foi decorrente do controle morfológico exercido pelas rochas de praia que estão dispostas paralelamente à linha de costa, no contato da praia emersa com a submersa. O que se observou foi que as rochas de praia funcionam como um aparato de proteção para a estrutura rígida à sua retaguarda, o que impede uma melhor compreensão do seu funcionamento enquanto estrutura que objetiva dissipar a energia de ondas e reter os sedimentos ao longo do perfil.

No perfil S3, não foi possível avaliar a relação da estrutura com o balanço sedimentar, pois a obra desmoronou há alguns meses. O que houve foi reflexo dos degraus espalhados pela face de praia que acabaram por funcionar como um enrocamento, retendo areias na parte de trás.

No perfil S4, o que se observou foi a erosão da parte superior do perfil com deposição na zona submersa, o que é normal. Nesse ponto, a robustez da praia foi responsável por dissipar parte da energia da agitação marítima, resguardando a obra. Nesse trecho, também não foi possível afirmar que a estrutura de proteção foi a única responsável pela estabilização do perfil, já que o ganho de areia neste setor advém, em sua maior parte, da erosão da seção 3 .

De forma geral, foi possível inferir que houve uma relação direta de erosão e deposição entre as seções 1 e 2 e 3 e 4 . Quando houve erosão nas seções a montante (1 e 3), houve ganho imediato nas seções a jusante ( 2 e 4 ). Designadamente, um componente importante de transporte lateral de areias.

Os resultados comparativos do perfil inicial e do perfil pós-ressaca do mar demonstram um baixo poder de resiliência ambiental: nesse ínterim, não houve recuperação integral de nenhum trecho monitorado. Essa situação foi evidente em todos os perfis com contínua erosão da alta praia, à exceção da seção 2 . As únicas seções que apresentaram relativa recuperação da berma foram a 2 e a 5 .

As respostas morfológicas observadas através do balanço sedimentar da praia (nas cinco seções de monitoramento) permitiram identificar que a onda foi a principal forçante hidrodinâmica da ressaca do mar em causa. Contudo, a sua associação com as máximas amplitudes de maré permitiu a indução de alterações volumétricas na alta praia, com consecutivo transporte transversal e longitudinal de areias. A profundidade máxima de remobilização sedimentar ativa foi a de $3,2 \mathrm{~m}$ para o evento analisado.

Os resultados apresentados podem auxiliar na gestão costeira do Icaraí, visto que as decisões de intervenções ordenadas nessa praia não consideraram fatores como a dinâmica costeira local durante eventos de ressaca do mar, a disponibilidade de sedimentos, as condições morfodinâmicas e a capacidade de resiliência do ambiente. Logo, os trechos costeiros protegidos (S2 a S4) não apresentaram a eficiência projetada. Portanto, gerir o litoral é, antes de mais nada, conhecer o ambiente e sua capacidade de suporte. 


\section{AGRADECIMENTOS}

Ao $\mathrm{CNPq}$ pelo financiamento do projeto "Impactos costeiros no litoral de Caucaia (Ceará, Brasil) induzidos pelas obras costeiras construídas a sotamar e pelas ressacas do mar (Processo: 483811/2013-0) e pela concessão de uma bolsa de iniciação científica. À FUNCAP pela concessão de duas bolsas de iniciação científica. À Universidade Estadual Vale do Acaraú pela infraestrutura e apoio na realização do projeto. Aos laboratórios de Oceanografia Geológica da UFC e de Geologia e Geomorfologia Costeira e Oceânica da UECE, pela parceria na realização dos experimentos de campo e análise laboratorial.

\section{REFERÊNCIAS BIBLIOGRÁFICAS}

1. Weschenfelder J, Ayoup Zouain RN. Variabilidade morfodinâmica das praias oceânicas entre Imbé e Arroio do Sal, RS, Brasil. Pesquisas em Geociências. 2002 Jan-Jun;29(1):3-13.

2. Faria Jr LEC, Marçal MS, Pinheiro RVL. A dinâmica sedimentar da praia do Maçarico/Salinópolis e sua importância para a geologia da região costeira do Estado do Pará. In: Congresso da Associação Brasileira de Estudos do Quaternário-ABEQUA; 1987 Jul 6-12; Porto Alegre, RS: p. 343-356.

3. Alves MMS, Coelho JS, Mendes RML, Kawamoto MS. Variabilidade morfológica do perfil da praia estuarina Barra Velha. In: Simpósio de Geologia da Amazônia-SGA; 2013 Set 22-26; Amazônia, Belém: p. $1-5$.

4. Busman DV, Carneiro IAM, Barbosa VM, Gregorio MAS, Albuquerque LA, Pereira LCC. Morfologia da Praia de Ajuruteua-PA (Brasil), durante uma maré equinocial de sizígia. In: II Congresso sobre planejamento e gestão das zonas costeiras dos países de expressão portuguesa, IX Congresso da Associação Brasileira de Estudos do Quaternário, II Congresso do Quaternário dos Países de Língua Ibéricas; 2003 Out 12-16; Recife, Pernambuco: p. 1-3.

5. Paula DP, Farrapeira Neto CA, Souza MAL, Dias JMA. Alterações morfológicas na Praia do Icaraí (Caucaia-Ceará) após a construção de um dissipador de energia para controle da erosão costeira. Revista GEONORTE. 2014 Out;10(2):7- 11.

6. Pond S, Pickard GL. Introductory Dynamical Oceanography. Vancouver (EUA): 2. Ed. Butterworth Heinemann; 1986. $321 \mathrm{p}$.

7. Vellinga P. Beach and dune erosion during storm surges [tese]. Roterdã (Netherlands): Delft University of Technology; $1982.200 \mathrm{p}$.

8. Ferreira O. Storm groups versus extreme single storms: predicated erosion and management consequences. Journal of Coastal Research. 2005 Out;SI(42):221-227.

9. Silva AMC, Vaz MVA, Neumann VH. Short-term changes and longshore transport on a steep fine sand beach: the example of the Itamaracá Island, NE Brazil. Estudos Geológicos. 2007 Jan-Jun;17(1):71-84.

10. Almeida LP, Ferreira Ó, Pacheco A. Thresholds for morphological changes on an exposed sandy beach as a function of wave height. Earth Surface Processes and Landforms. 2010 Set;36(4):523-532, doi: 10.1002/esp.2072.

11. Faraco KR. Comportamento morfodinâmico e sedimentológico da Praia dos Ingleses- Ilha de Santa Catarina-SC, durante o período de 1996-2001 [dissertação]. Florianópolis(SC): Universidade Federal de Santa Catarina; 2003. 125 p.

12. Montefalcone M, Parravicini V, Vacchi M, Albertelli G, Ferrari M, Morri C, Bianchi CN. Human influence on seagrass habitat fragmentation in NW Mediterranean Sea. Estuarine, Coastal and Shelf Science. 2010 Jan;86(2):292-298, doi: 10.1016/j.ecss.2009.11.018.

13. Floor JA. Oceanography: Waves theory and principles of waves, how they work and what causes them. 2000. Disponível em: <http://www.seafriends.org.nz/oceano/waves.htm> Acesso: 10 Jan 2016.

14. Pye K, Saye S, Blott S. Sand dune processes and management for flood and coastal defence. London (England): Royal Holloway University of London, and Kenneth Pye Associates Ltd; 2007. 89 p.

15. Toldo JR EE, Motta LM, Almeida LESB, Nunes JCR. Large morphological change linked to the sediment budget in the Rio Grande do Sul coast. In: $7^{\text {th }}$ International Conference on Coastal Dynamics: Proceedings of Coastal Dynamics; 2013 Jun 24-28; Bordeaux, France: p. 1687-1696.

16. Komar PD, McDougal WG. Coastal erosion and engineering structures: the Oregon experience. Journal of Coastal Research.1988 Sep;SI(4):77-92.

17. Dias JMA. Estudo de avaliação da situação ambiental e proposta de medidas de salvaguarda para a faixa costeira Portuguesa. Faro (Portugal): Universidade do Algarve; 1993. 137 p.

18. Zyserman JA, Johnson HK, Zanuttigh B, Martinelli L. Analysis of far-field erosion induced by lowcrested rubble-mound structures. Coastal Engineering. 2005 Nov;52(10):977-994, doi: 10.1016/j.coastaleng.2005.09.013. 
19. Zasso LA, Barbosa EG, Gruber NLS. Alterações na deriva litorânea e no balanço sedimentar nas adjacências do Rio Mampituba/RS-SC. GRAVEL. 2013 Dez;11(1):1-17.

20. Paula DP, Dias JMA, Souza AL, Farrapeira Neto CA, Barros EL. Monitorização de curto prazo da Praia do Icaraí (Caucaia, Ceará, Brasil) após construção de estrutura rígida do tipo Bagwall para controle da erosão. In: VII Congresso de Sobre Planejamento e Gestão das Zonas Costeiras dos Países de Expressão Portuguesa e $11^{\circ}$ SILUSBA; 2013 Mai 24-30; Maputo, Moçambique: p. 1-10.

21. Moura MR, Abreu Neto JC, Sousa PHGO. Geoprocessamento aplicado à análise da evolução da linha de costa da Praia do Icaraí, Caucaia, Ceará. In: $1^{\circ}$ Simpósio de Integração das Ciências do Mar (I SICMar); 2012 Ago 27-31; São Paulo, SP: p. 1-2.

22. Silva AC, Façanha P, Bezerra C, Araujo A, Pitombeiras E. Características das ondas "Sea" e "Swell" observadas no litoral do Ceará-Brasil: variabilidade anual e inter-anual. Tropical Oceanography. 2011 Dez;39(2):123-132, doi: 10.5914/to.2011.055.

23. Birkemeier WA. Fast Accurate Two-Person Beach Survey. Vicksburg, Mississippi, USA: Coastal Engineering Technical Aid 81-11. U.S Army Engineer Waterways Experiment Station; 1981. 22 p.

24. Souza CRG. Praias arenosas oceânicas do estado de São Paulo (Brasil): síntese dos conhecimentos sobre morfodinâmica, sedimentologia, transporte costeiro e erosão costeira. Revista do Departamento de Geografia - USP. 2012 Jul-Dez; Volume Especial RDG 30 anos(1):307-371, doi: 10.11606/rdg.2012.89.964.

25. CEARAPORTOS - Companhia de Integração Portuária do Ceará. Relatório final dos estudos em modelo físico reduzido de agitação do Porto do Pecém-Ce. Rio de Janeiro, RJ: INPH - Instituto de Pesquisas Hidroviárias (No. 71/96); 1996. 38 p. 